\title{
IMPORTÂNCIA DO PERÍODO DE PRÉ-FLORAÇÃO NA PRODUTIVIDADE DO FEIJOEIRO ${ }^{1}$
}

\author{
Agostinho Dirceu Didonet ${ }^{2}$
}

\begin{abstract}
IMPORTANCE OF THE PRE-FLOWERING

GROWTH STAGE FOR COMMON BEAN YIELD

The objective of the present study was to determine the importance of the pre-flowering growth stage for common bean yield. In two assays, the common bean BRS-Pérola, BRSValente and Jalo Precoce cultivars were sown at five different dates, from April to August, in 2001 and 2002, at Embrapa Arroz e Feijão, in Santo Antônio de Goiás, Goiás State, Brazil. The experiments were carried out under conventional tillage, in a randomized split-plot block design, with four repetitions. Physiological parameters related to common bean plant growth, development and yield were correlated with temperatures and solar radiation incidence, during the pre-flowering plant growth period. Increases of minimum temperature, solar radiation, and $\mathrm{N}$ absorption rate, and decrease in $\mathrm{N}$ efficiency use, up to the third trifoliolate leaf stage, were correlated with yield reduction. The phenological period between emergence and third trifoliolate leaf is the most important one for common bean yield determination, when compared with the total pre-flowering period.
\end{abstract}

KEY-WORDS: Phaseolus vulgaris; common bean development; temperature; solar radiation.

\section{INTRODUÇÃO}

No Brasil, o feijoeiro comum é cultivado, praticamente, em todos os meses do ano, com e sem irrigação, em diferentes épocas e datas de semeadura, tendo reflexos positivos e negativos na produtividade, como consequência das condições de ambiente associado às datas de semeadura (Miranda et al. 1993, Ramalho et al. 1993, Carbonell \& Pompeu 1997, 2000). A diversidade de condições onde é cultivado, incluindo latitudes entre $52^{\circ} \mathrm{N}$ e $32^{\circ} \mathrm{S}$, do nível do mar até altitudes superiores a $3.000 \mathrm{~m}$, em sistemas de produção altamente tecnificados e em cultivos de subsistência, faz com que o feijoeiro cresça sob temperaturas bem distantes daquelas consideradas ótimas (Schoonhoven \& Voysest 1991, Rainey \&

\section{RESUMO}

Objetivou-se verificar a importância do período da emergência à pré-floração, na produtividade do feijoeiro. Em dois ensaios, as cultivares BRS-Pérola, BRS-Valente e Jalo Precoce foram semeadas em cinco épocas, entre abril e agosto de 2001 e 2002, em área experimental da Embrapa Arroz e Feijão, em Santo Antônio de Goiás, GO, próxima a uma estação meteorológica. Os ensaios foram instalados em sistema convencional de preparo de solo, em delineamento experimental de blocos ao acaso, com parcelas subdivididas e quatro repetições. Características fisiológicas relacionadas a crescimento, desenvolvimento e produtividade foram correlacionadas com temperaturas e radiação solar incidentes no período. Aumentos na temperatura mínima, radiação solar e na taxa de absorção de $\mathrm{N}$ e diminuição na eficiência do uso de $\mathrm{N}$, até o terceiro trifólio, foram correlacionados com redução na produtividade. Na fase de pré-floração, o subperíodo entre a emergência e o terceiro trifólio é o mais importante para a determinação do rendimento de grãos do feijoeiro.

PALAVRAS-CHAVES: Phaseolus vulgaris; desenvolvimento do feijoeiro; temperatura; radiação solar.

Griffiths 2005). Consequentemente, a sua produtividade pode variar entre menos de $500 \mathrm{~kg} / \mathrm{ha}$ e mais de $4.000 \mathrm{~kg} / \mathrm{ha}$, em monocultivos intensivos, principalmente como resultado de melhorias no controle de doenças, pragas e controle das restrições nutricionais, além de outros tratos culturais (Graham \& Ranalli 1997).

Em sistemas de produção de alta produtividade, como aqueles irrigados durante o inverno, no Centro-Oeste do Brasil, as práticas de manejo visam ao maior acúmulo possível de fitomassa pelas plantas. Além disto, é necessária uma eficiente translocação dos fotoassimilados contidos nesta fitomassa para os grãos (Pereira 1989, Didonet 2005). Assim, para maximizar o rendimento, é necessário que as práticas de manejo potencializem os componentes do 
rendimento (White \& Izquierdo 1989, Graham \& Ranalli 1997, Miflin 2000). Dentre os componentes do rendimento, alguns são intrínsecos à cultivar, enquanto outros dependem do ambiente de crescimento da cultura. Temperatura e disponibilidade de energia luminosa são fatores primordiais na determinação dos componentes de rendimento (Samach \& Wigge 2005). O aumento da temperatura incrementa a taxa de florescimento e reduz o tempo para a floração, com diminuição no período efetivo de produção e acúmulo de fotoassimilados (Ribeiro et al. 2004, Porch 2006, Silva et al. 2007).

Taxas de crescimento e desenvolvimento, metabólicas, de respiração basal, de assimilação e distribuição interna de nutrientes e fotoassimilados, de relações hídricas e de acúmulo de determinados metabólitos podem ser alteradas, em consequência do aumento da temperatura ambiente (Pastenes \& Horton 1996, Hikosaka 1997, Jeuffroy \& Ney 1997, Atkin \& Tjoelker 2003, Hansen et al. 2006, Sage \& Kubien 2007, Shao et al. 2007, Wahid et al. 2007, Guy et al. 2008). O estresse térmico ao qual as plantas anuais são submetidas, quando semeadas em diferentes épocas do ano, pode provocar alterações no metabolismo celular, como reação a estas flutuações térmicas (Mittler 2006, Shulaev et al. 2008). No feijoeiro, dependendo da fase fenológica em que a alta temperatura incide, pode haver abortamento de flores e vagens, redução no vingamento e na formação dos grãos (Gross \& Kigel 1994). Temperaturas altas também promovem crescimento vegetativo exuberante, encurtamento do ciclo de vida e desequilíbrio entre a produção, distribuição e uso de fotoassimilados (White \& Izquierdo 1989).

O objetivo deste trabalho foi determinar a dependência de diferentes condições de temperatura e radiação impostas ao feijoeiro, até o início da floração, durante o período de inverno, em características fisiológicas e produtividade das plantas.

\section{MATERIAL E MÉTODOS}

Dois ensaios foram conduzidos em cinco épocas de semeadura, de meados de abril a meados de agosto de 2001 e 2002 (Tabela 1), em sistema convencional de preparo de solo. Utilizaram-se as cultivares de feijão Jalo Precoce, BRS-Pérola e BRS-Valente. A parcela experimental foi constituída por dez linhas de $10 \mathrm{~m}$ de comprimento, espaçadas em $0,50 \mathrm{~m}$, totalizando $50 \mathrm{~m}^{2}$ de área útil, em Latossolo
Tabela 1. Data de semeadura das cultivares de feijoeiro Jalo Precoce, BRS-Pérola e BRS-Valente (Santo Antônio de Goiás, GO, 2001/2002).

\begin{tabular}{ccc}
\hline \multirow{2}{*}{ Época } & 2001 & 2002 \\
\cline { 2 - 3 } & \multicolumn{2}{c}{ Data de semeadura (dia) } \\
\hline 1 & 27 abril & 11 abril \\
2 & 28 maio & 09 maio \\
3 & 28 junho & 06 junho \\
4 & 26 julho & 05 julho \\
5 & 24 agosto & 07 agosto \\
& Data de semeadura (dia juliano) \\
\hline 1 & 117 & 101 \\
2 & 148 & 129 \\
3 & 179 & 157 \\
4 & 207 & 186 \\
5 & 236 & 219 \\
\hline
\end{tabular}

Vermelho distrófico, textura argilosa, na área experimental da Embrapa Arroz e Feijão, em Santo Antônio de Goiás, GO, próxima a uma estação meteorológica. O cálculo da quantidade de calcário aplicada antes do preparo do solo foi efetuado com base na análise do solo.

No sulco de plantio, aplicou-se o equivalente a $450 \mathrm{~kg} / \mathrm{ha}$ do adubo formulado 4:28:20 + Zn. Nos estádios fenológicos V3 - primeiro trifólio e V4 terceiro trifólio, foram aplicados, em cobertura, o equivalente a $250 \mathrm{~kg} /$ ha de sulfato de amônia. A densidade de plantas foi ajustada para 12 a 13 plantas $/ \mathrm{m}$.

$\mathrm{O}$ delineamento experimental foi de blocos ao acaso, em parcelas subdivididas, onde as cultivares formaram as parcelas principais e as épocas de semeadura as subparcelas. Para o controle da irrigação, foram usados tensiometros, instalados a $15 \mathrm{~cm}$ de profundidade, e irrigações por aspersão foram feitas assim que a média das leituras se situava na faixa de $30 \mathrm{kPa}$ a $40 \mathrm{kPa}$.

O controle de pragas e doenças foi preventivo. Não se observaram sintomas de deficiências nutricionais nas plantas. A fitomassa total seca acumulada na parte aérea de $1 \mathrm{~m}$ de plantas, nos estádios fenológi$\cos \mathrm{V} 3$, V4 e R5 (aparecimento de botões florais até início da floração), foi determinada após a coleta e secagem em estufa de ventilação forçada, a $65^{\circ} \mathrm{C}$, até atingir massa constante. Após a pesagem e a moagem, determinou-se o nitrogênio total ( $\mathrm{N}$ total) acumulado na fitomassa, pelo método semimicro Kjeldhal, conforme descrito por Tedesco et al. (1995). Antes da determinação da fitomassa total seca, as folhas das plantas foram usadas na determinação da área foliar. Também, se avaliou, diariamente, o número de flores e vagens caídas em uma tela colocada no solo. Para 
o cálculo do percentual de abortamento, as flores e as vagens caídas, acrescidas das vagens presentes nas plantas, na maturação fisiológica (estádio R9), foram consideradas como número total de flores. $\mathrm{O}$ rendimento de grãos, com $13 \%$ de água, foi avaliado em $16 \mathrm{~m}^{2}$ de área útil.

Com os dados do acúmulo de fitomassa e de $\mathrm{N}$ total, do tempo de duração entre a emergência e R5 e do índice de área foliar (IAF), calcularam-se as taxas diárias de acúmulo de fitomassa e de $\mathrm{N}$ total; a quantidade de fitomassa acumulada por unidade de $\mathrm{N}$ absorvida (eficiência do uso do $\mathrm{N}$ ); o aumento de fitomassa da parte aérea, por unidade de área foliar e de tempo (taxa assimilatória líquida - TAL); a área foliar específica (AFE); a razão de área foliar (RAF) e a razão de massa foliar (RMF) (White \& Izquierdo 1989). O coeficiente de correlação entre as variáveis e sua significância foram determinados através da ferramenta de análise do programa Microsoft Excel.

\section{RESULTADOS E DISCUSSÃO}

Temperaturas máximas (Tmax) e mínimas (Tmin) e a radiação solar global (Rad) incidentes nas plantas de feijoeiro, no período entre a emergência (E) e R5, foram correlacionadas, positivamente, com o N acumulado na parte aérea (NT R5) e com as taxas diárias de acúmulo de $\mathrm{N}$, neste período (TAN E/R5) (Tabela 2). Houve correlação positiva entre E/R5 e NT R5, negativa entre AT V4/R5 e TAN E/R5 e nenhuma entre a amplitude térmica (AT), nos subperíodos E/V4, V4/R5 e E/R5, e NT R5 (Tabela 2).

A Tmin incidente no dossel, no período V4/ R5, apresentou correlação positiva, tanto com o NT R5 quanto com a TAN E/R5, ao passo que a Tmax não apresentou correlação com estes parâmetros (Tabela 1). A TAN E/V4, RAD E/V4, Tmin E/V4 e Tmin E/R5 apresentaram correlação negativa com o rendimento de grãos (RG) do feijoeiro, enquanto a Tmax e AT incidente até R5, bem como os períodos V4/R5 e E/R5, não foram correlacionados com o RG (Tabela 2).

Estas observações evidenciam a importância da Tmin e da Rad incidentes até R5, na determinação da produtividade de grãos do feijoeiro, de tal maneira que, nas condições estudadas, pode-se esperar redução no RG, sempre que houver aumento na Tmin e na Rad. Esta elevação na Tmin E/R5 e RAD E/R5 induziu, diretamente, a planta do feijoeiro a absorver maior quantidade de N (aumento na NT R5 e TAN E/ R5), tendo reflexo inverso no RG. Assim, nem sempre se podem esperar aumentos no RG do feijoeiro, mesmo com alta disponibilidade de $\mathrm{N}$ (aplicação de $\mathrm{N}$ fertilizante), para as plantas, no período E/R5, em situações de cultivo onde ocorre elevação na Tmin e na Rad, neste período. A redução de ciclo em E/ R5, decorrente do aumento na temperatura (Pimentel 1998, White \& Izquierdo 1989), promoverá menor acúmulo de NT R5, mesmo com aumento na TAN E/V4, o que resultará em redução no RG.

Tabela 2. Coeficientes de correlação entre dados fenológicos e de clima e rendimento de grãos, acúmulo e taxa de absorção de nitrogênio total e abortamento de flores e vagens retidas, determinados nas cultivares de feijoeiro Pérola, Jalo Precoce e BRS-Valente, cultivadas em cinco épocas de semeadura, no inverno (Santo Antônio de Goiás, GO, 2001/2002).

\begin{tabular}{lccccc}
\hline & RG & NT R5 & TAN E/R5 & Flores abortadas (\%) & Vagens retidas (\%) \\
\hline Tmax E/V4 & $\mathrm{ns}$ & $0,55^{* *}$ & $0,67^{* *}$ & $-0,48^{* *}$ & $0,41^{*}$ \\
Tmax V4/R5 & $\mathrm{ns}$ & $\mathrm{ns}$ & $\mathrm{ns}$ & $-0,56^{* *}$ & $0,53^{* *}$ \\
Tmax E/R5 & $\mathrm{ns}$ & $0,53^{* *}$ & $0,57^{* *}$ & $-0,55^{* *}$ & $0,50^{*}$ \\
Tmin E/V4 & $-0,48^{* *}$ & $0,54^{* *}$ & $0,75^{* *}$ & $\mathrm{~ns}$ & $\mathrm{~ns}$ \\
Tmin V4/R5 & $\mathrm{ns}$ & $0,47^{* *}$ & $0,62^{* *}$ & $\mathrm{~ns}$ & $\mathrm{~ns}$ \\
Tmin E/R5 & $-0,44^{*}$ & $0,55^{* *}$ & $0,74^{* *}$ & $\mathrm{~ns}$ & $\mathrm{~ns}$ \\
AT E/V4 & $\mathrm{ns}$ & $\mathrm{ns}$ & $\mathrm{ns}$ & $-0,63^{* *}$ & $0,61^{* *}$ \\
AT V4/R5 & $\mathrm{ns}$ & $\mathrm{ns}$ & $-0,39^{*}$ & $\mathrm{~ns}$ & $0,48^{* *}$ \\
AT E/R5 & $\mathrm{ns}$ & $\mathrm{ns}$ & $\mathrm{ns}$ & $-0,51^{* *}$ & $0,59^{* *}$ \\
Rad E/V4 & $-0,39 *$ & $0,50^{* *}$ & $0,57^{* *}$ & $-0,50^{* *}$ & $0,43^{*}$ \\
Rad V4/R5 & $\mathrm{ns}$ & $\mathrm{ns}$ & $\mathrm{ns}$ & $-0,36^{*}$ & $0,41^{*}$ \\
Rad E/R5 & $\mathrm{ns}$ & $0,45^{*}$ & $0,37^{*}$ & $-0,53^{* *}$ & $0,51^{* *}$ \\
V4/R5 dias & $\mathrm{ns}$ & $0,65^{* *}$ & $\mathrm{~ns}$ & $\mathrm{~ns}$ & $\mathrm{~ns}$ \\
E/R5 dias & $\mathrm{ns}$ & $0,50^{* *}$ & $\mathrm{~ns}$ & $\mathrm{~ns}$ & $\mathrm{~ns}$ \\
TAN E/V4 & $-0,37 *$ & $\mathrm{~ns}$ & $\mathrm{~ns}$ & $\mathrm{~ns}$ & $\mathrm{~ns}$ \\
\hline
\end{tabular}

RG: rendimento de grãos $\left(\mathrm{g} / \mathrm{m}^{2}\right)$; E: emergência; V4: terceiro trifólio; R5: aparecimento dos botões florais; NT: nitrogênio total acumulado (g/m²); TAN: taxa de acúmulo de nitrogênio total ( $\left.\mathrm{mg} \mathrm{de} \mathrm{N} / \mathrm{m}^{2} / \mathrm{dia}\right)$; Tmax: temperatura máxima média $\left({ }^{\circ} \mathrm{C}\right)$; Tmin: temperatura mínima média $\left({ }^{\circ} \mathrm{C}\right)$; AT: amplitude térmica, diferença entre a temperatura máxima e mínima $\left({ }^{\circ} \mathrm{C}\right)$; Rad: radiação global média incidente $\left(\mathrm{MJ} / \mathrm{m}^{2} /\right.$ dia $) ;$ *: significativo $(\mathrm{p}<0,05)$; **: significativo $(\mathrm{p}<0,01)$; ns: não significativo. 
Tmax, AT e Rad, incidentes no período E/ $\mathrm{R} 5$, tiveram correlação negativa com o percentual de flores abortadas e positiva com o percentual de retenção de vagens, enquanto Tmin, E/R5 e TAN E/ V4 não tiveram nenhuma correlação com o abortamento de flores ou retenção de vagens (Tabela 2). Estes resultados estão de acordo com aqueles obtidos por outros estudos, em que os aumentos nas temperaturas mínimas são mais prejudiciais ao feijoeiro comum quando incidentes na fase reprodutiva do feijoeiro (Gross \& Kigel 1994). Por outro lado, estas condições, provavelmente, favoreceram uma maior retenção de vagens do que a capacidade que as plantas teriam em sustentá-las (Didonet \& Vitória 2006), possivelmente, explicando o efeito negativo do aumento na Tmin e Rad incidentes nos períodos $\mathrm{E} /$ V4 e E/R5, na produtividade de grãos dos feijoeiros.

As correlações entre Tmax, Tmin, AT, Rad, dias até R5, datas de E, V4, R5 em dias julianos (DJ) e EUN E/V4 e FM R5, TAFM E/R5 e EUN E/R5 são mostradas na Tabela 3. Nas condições estudadas, a temperatura, a radiação solar e a duração (em dias) em V4/R5 tiveram efeito direto (correlação +) na FM R5 e na TAFM E/R5, nas plantas de feijoeiro (Tabela 3). A duração, em dias, em E/V4, certamente decorrente de menores temperaturas, apresentou correlação inversa (-) em TAFM E/R5, mas não teve nenhuma correlação com a FM R5 (Tabela 3). Portanto, maior FM R5, nas plantas de feijoeiro estudadas, parece ser diretamente dependente da maior duração (dias) do período fenológico em V4/R5 e não da duração (dias) do período fenológico E/V4.

Maior eficiência no uso de $\mathrm{N}$, em termos de acumulação de fitomassa na parte aérea do feijoeiro até o R5 - EUN E/R5, foi dependente de Tmin E/ R5 mais baixas (correlação -) e de maior AT E/R5 (correlação +) (Tabela 3). Nem a Tmax e nem a Rad incidentes tiveram efeito na EUN E/R5 das plantas, que foi diretamente proporcional (correlação + ) à duração do tempo em E/R5 (Tabela 3). Como a temperatura tem efeito acentuado no controle do desenvolvimento do feijoeiro, espera-se que um aumento de temperatura acelere o desenvolvimento, reduzindo o número de dias para que as plantas iniciem a floração, com consequente redução da eficiência no uso de nitrogênio e acumulação de biomassa (White \& Singh 1991, Welsh et al. 1995, White et al. 1994, Abebe et al. 1998).

À medida que a semeadura, E, V4 ou R5 foram sendo efetuados nos meses seguintes, a partir
Tabela 3. Coeficientes de correlação entre dados fenológicos e de clima e rendimento de grãos, acúmulo e taxa de acúmulo de fitomassa total e acúmulo de fitomassa por unidade de nitrogênio absorvido, determinados nas cultivares de feijoeiro Pérola, Jalo Precoce e BRS-Valente, obtidos em cinco diferentes épocas de semeadura, no inverno (Santo Antônio de Goiás, GO, 2001/2002).

\begin{tabular}{lcccc}
\hline & RG & FM R5 & TAFM E/R5 & EUN E/R5 \\
\hline Tmax E/V4 & $\mathrm{ns}$ & $0,46^{* *}$ & $0,65^{* *}$ & $\mathrm{~ns}$ \\
Tmax E/R5 & $\mathrm{ns}$ & $0,46^{* *}$ & $0,56^{* *}$ & $\mathrm{~ns}$ \\
Tmin E/V4 & $-0,48^{* *}$ & $0,38^{*}$ & $0,67^{* *}$ & $\mathrm{~ns}$ \\
TminV4/R5 & $\mathrm{ns}$ & $\mathrm{ns}$ & $0,51^{* *}$ & $\mathrm{~ns}$ \\
Tmin E/R5 & $-0,44^{*}$ & $0,38^{*}$ & $0,65^{* *}$ & $-0,36^{*}$ \\
AT E/R5 & $\mathrm{ns}$ & $\mathrm{ns}$ & $\mathrm{ns}$ & $0,36^{*}$ \\
Rad E/V4 & $-0,39^{*}$ & $0,43^{*}$ & $0,56^{* *}$ & $\mathrm{~ns}$ \\
Rad E/R5 & $\mathrm{ns}$ & $0,40^{*}$ & $0,36^{*}$ & $\mathrm{~ns}$ \\
E DJ & $\mathrm{ns}$ & $\mathrm{ns}$ & $\mathrm{ns}$ & $-0,41^{*}$ \\
V4 DJ & $\mathrm{ns}$ & $\mathrm{ns}$ & $\mathrm{ns}$ & $-0,39^{*}$ \\
R5 DJ & $\mathrm{ns}$ & $\mathrm{ns}$ & $\mathrm{ns}$ & $-0,37^{*}$ \\
E/V4 dias & $\mathrm{ns}$ & $\mathrm{ns}$ & $-0,49^{* *}$ & $\mathrm{~ns}$ \\
V4/R5 dias & $\mathrm{ns}$ & $0,79 * *$ & $\mathrm{~ns}$ & $\mathrm{~ns}$ \\
E/R5 dias & $\mathrm{ns}$ & $0,66^{* *}$ & $\mathrm{~ns}$ & $0,42^{*}$ \\
EUN E/V4 & $0,42^{*}$ & $\mathrm{~ns}$ & $\mathrm{~ns}$ & $\mathrm{~ns}$ \\
\hline
\end{tabular}

$\mathrm{RG}$ : rendimento de grãos $\left(\mathrm{g} / \mathrm{m}^{2}\right)$; E: emergência; V4: terceiro trifólio; R5: aparecimento dos botões florais; FM: fitomassa total acumulada no R5 $\left(\mathrm{g} / \mathrm{m}^{2}\right)$; TAFM: taxa de acúmulo de fitomassa em E/R5 (g de MS/m²/dia); EUN: eficiência de uso do $\mathrm{N}$ em E/R5 (mgFM/mgN); Tmax: temperatura máxima média no período $\left({ }^{\circ} \mathrm{C}\right)$; Tmin: temperatura mínima média no período $\left({ }^{\circ} \mathrm{C}\right)$; AT: amplitude térmica no período $\left({ }^{\circ} \mathrm{C}\right)$; Rad: radiação solar global média incidente no período $\left(\mathrm{MJ} / \mathrm{m}^{2} /\right.$ dia); DJ: dia juliano; *: significativo $(\mathrm{p}<0,05)$; ${ }^{* *}$ : significativo $(\mathrm{p}<0,01)$; ns: não significativo.

de meados de abril, a EUN E/R5 foi sendo reduzida (correlação -) (Tabela 3). Isto ocorreu porque quanto mais tardia foi a semeadura, mais elevadas foram a Tmin e a Rad incidentes no período até R5. Por outro lado, quanto maior foi a EUN E/V4, maior foi o RG alcançado pelas plantas (correlação + ), indicando que não foi a alta disponibilidade ou altas taxas de absorção de nitrogênio, mas sim a sua eficiência de uso, nesta fase, é que foi importante para determinar maior produtividade nos feijoeiros testados (Tabela 3).

As correlações entre IAF R5, AFE R5, RAF R5, RMF R5, TAL E/R5 e Tmin, Tmax, Rad, AT, TAFM, TAN e EUN são mostradas na Tabela 4. O IAF R5 apresentou variação diretamente proporcional (correlação + ) às variações de Tmax e Tmin, observadas no período entre E e R5 das plantas de feijoeiro testadas, enquanto a AFE R5 e RAF R5 variaram de forma direta (correlação + ) somente de acordo com as variações de Tmin (Tabela 4). A TAL $\mathrm{E} / \mathrm{R} 5$ variou de forma inversa (correlação -) somente com relação às variações da Tmin, ao passo que a RMF R5 não apresentou nenhuma correlação com 
Tabela 4. Coeficientes de correlação entre dados fenológicos e de clima, acúmulo e taxa de acúmulo de fitomassa total e acúmulo de fitomassa por unidade de nitrogênio absorvido, índice de área foliar, área foliar específica, razão de área e fitomassa seca foliar e taxa assimilatória líquida, no período compreendido entre E e R5, determinados nas cultivares de feijoeiro Pérola, Jalo Precoce e BRS-Valente, cultivadas em cinco diferentes épocas de semeadura, no inverno (Santo Antônio de Goiás, GO, 2001/2002).

\begin{tabular}{|c|c|c|c|c|c|}
\hline & IAF R5 & AFE R5 & RAF R5 & RMF R5 & TAL E/R5 \\
\hline Tmax E/R5 & $0,48 * *$ & ns & ns & ns & ns \\
\hline Tmax E/V4 & $0,54 * *$ & $0,39 *$ & ns & ns & ns \\
\hline Tmin E/V4 & $0,62 * *$ & $0,54 * *$ & $0,45^{*}$ & ns & $-0,39 *$ \\
\hline TminV4/R5 & $0,53 * *$ & $0,47^{*}$ & $0,39 *$ & ns & $-0,45^{*}$ \\
\hline Tmin E/R5 & $0,63 * *$ & $0,55^{* *}$ & $0,46^{*}$ & $\mathrm{~ns}$ & $-0,45^{*}$ \\
\hline AT V4/R5 & $-0,36^{*}$ & $-0,45^{*}$ & $-0,44^{*}$ & ns & ns \\
\hline AT E/R5 & ns & $-0,42 *$ & $-0,43^{*}$ & ns & ns \\
\hline Rad E/V4 & $0,60 * *$ & $0,46^{*}$ & $0,39 *$ & ns & $-0,52 * *$ \\
\hline Rad V4/R5 & ns & $-0,42 *$ & $-0,44^{*}$ & ns & $0,36^{*}$ \\
\hline TAFM E/R5 & $0,77 * *$ & $0,50 * *$ & $0,36^{*}$ & $-0,53 * *$ & $-0,41^{*}$ \\
\hline TAN E/R5 & $0,74 * *$ & $0,56 * *$ & $0,46^{*}$ & ns & $-0,43 *$ \\
\hline EUN E/R5 & ns & ns & ns & $-0,39 *$ & ns \\
\hline $\mathrm{RG}$ & ns & ns & ns & ns & ns \\
\hline
\end{tabular}

E: emergência; V4: terceiro trifólio; R5: aparecimento dos botões florais; IAF: índice de área foliar; AFE: área foliar específica $\left(\mathrm{m}^{2}\right.$ de área de folha/ $\mathrm{kg}$ de fitomassa seca foliar); RAF: razão de área foliar $\left(\mathrm{m}^{2}\right.$ de área de folha $/ \mathrm{kg}$ de fitomassa seca total); RMF: razão de massa foliar ( $\mathrm{g}$ de fitomassa seca foliar/g de fitomassa seca total); TAL: taxa assimilatória líquida no período fenológico ( $\mathrm{g}$ de fitomassa seca total $/ \mathrm{m}^{2}$ de área foliar/dia); TAFM: taxa de acúmulo de fitomassa durante o período ( $\mathrm{g}$ de $\mathrm{FM} / \mathrm{m}^{2} / \mathrm{dia}$ ); TAN: taxa de acúmulo de nitrogênio total durante o período ( $\mathrm{g}$ de $\mathrm{N} / \mathrm{m}^{2} /$ dia); EUN: eficiência de uso do $\mathrm{N}$ no período $(\mathrm{mgFM} / \mathrm{mgN}$ ); $\mathrm{RG}$ : rendimento de grãos $\left(\mathrm{g} / \mathrm{m}^{2}\right)$; Tmax: temperatura máxima média no período $\left({ }^{\circ} \mathrm{C}\right)$; Tmin: temperatura mínima média no período $\left({ }^{\circ} \mathrm{C}\right)$; AT: amplitude térmica, diferença entre a temperatura máxima e mínima no período $\left({ }^{\circ} \mathrm{C}\right)$; Rad: radiação solar global média incidente no período $\left(\mathrm{MJ} / \mathrm{m}^{2} / \mathrm{dia}\right) ;$ *: significativo $(\mathrm{p}<0,05)$; **: significativo $(\mathrm{p}<0,01)$; ns: não significativo.

as variações de Tmax ou Tmin (Tabela 4). O IAF R5, a AFE R5 e a RAF R5 se correlacionaram, positivamente, com o aumento na TAFM E/R5 e com a TAN E/R5, enquanto a RMF R5 e a TAL E/R5 apresentaram variação inversa (correlação -) com a RMF R5 e a TAL E/R5 (Tabela 4).

As variações na AT V4/R5 e AT E/R5 proporcionaram variações inversas (correlação -) no IAF R5, AFE R5 e RAF R5, não afetando a RMF R5 ou a TAL E/R5 (Tabela 4). As alterações na Rad E/V4, propiciaram alterações proporcionais (correlação + ) no IAF R5, AFE R5 e RAF R5, alterações indiretas (correlação -) na TAL E/R5 e nenhuma, com relação à RMF R5. Já as alterações na Rad V4/R5 apresentaram respostas contrárias àquelas proporcionadas pela Rad E/V4, nestes parâmetros (Tabela 4). À medida que a quantidade de biomassa alocada para as folhas aumentou (RMF R5), ocorreu redução na TAFM R5 e na EUN E/R5 (correlação -), nas plantas de feijoeiro testadas (Tabela 4). Isto indica que as plantas estão regulando a partição de $\mathrm{N}$ e fitomassa, para manter constante a relação entre a taxa de carboxilação e de regeneração da Rubisco, quando ocorrem as variações na temperatura de crescimento (Hikosaka et al. 2006).

Nem o IAF, a AFE, a RAF, a RMF ou a TAL, determinados até R5, tiveram efeito no RG (Tabela 4 e Figura 1), indicando que a possível influência destes parâmetros no RG poderia ser decorrente do efeito indireto da temperatura e da radiação incidentes no dossel.

Os efeitos negativos do aumento na Tmin, no RG do feijoeiro, podem ser decorrentes do excesso de IAF R5, proporcionando um autosombreamento prejudicial à produtividade, mesmo com aumento na Rad R5 (Figura 1). Tal afirmativa pode ser observada pela coincidência entre os menores valores de IAF, as maiores $\mathrm{AT}$ e os maiores $\mathrm{RG}$ verificados quando a emergência das plantas ocorreu entre os dias 150 e 200 do calendário juliano (Figura 1). É, também, neste período de emergência, que o aumento na AT, experimentado pelas plantas no estádio fenológico em V4/R5, fase de incremento expressivo em fitomassa, proporciona redução direta (correlação + ) no IAF avaliado no R5 (Tabela 4).

Os menores valores de IAF R5, observados quando a emergência das plantas ocorreu entre os dias julianos 150 e 200, coincidentes com as maiores AT E/R5 e com os maiores RG (Figura 1), demonstram que as cultivares de feijoeiro comum estudadas podem ter área foliar excessiva, dependendo da época de semeadura (Acosta-Gallegos et al. 1996).

Em semeaduras efetuadas fora da faixa, entre os dias julianos 150 e 200, os maiores valores de IAF coincidiram com as maiores TAN E/R5 e TAFM E/R5, além das maiores quantidades de N total acumulado na parte aérea das plantas, e com as menores TAL E/R5 (Figura 2). É possível, portanto, que, mesmo com alta disponibilidade de radiação solar, o excesso de área foliar tenha provocado autosombreamento, resultando em desbalanceamento nas relações fonte/dreno, contribuindo para limitar a produtividade de grãos, em épocas de semeadura onde a fase vegetativa coincide com menores amplitudes térmicas.

Normalmente, as folhas sombreadas alocam maiores quantidades de $\mathrm{N}$ e carboidratos para captar luminosidade, enquanto folhas a pleno sol direcionam mais $\mathrm{N}$ e carboidratos para a produção de energia e para o ciclo de Calvin, o que contribui para uma me- 

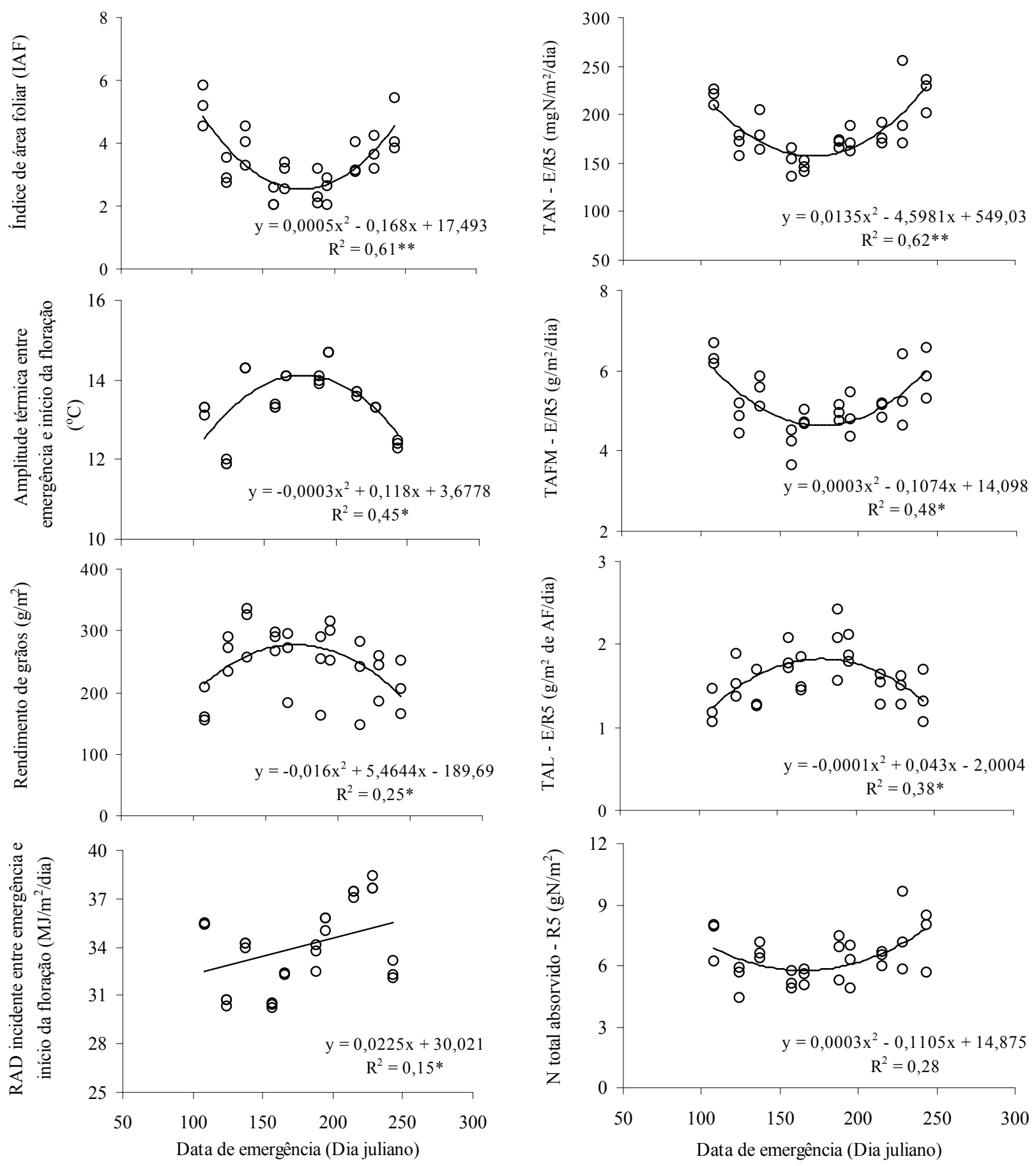

Figura 1. Variações no índice de área foliar (IAF), determinado no início da floração (estádio R5), na amplitude térmica e na radiação solar global (RAD), incidentes no período entre a emergência (E) e o início da floração (estádio R5), e rendimento de grãos, decorrentes da data de emergência de plantas de feijoeiro comum das cultivares BRS-Pérola, Jalo Precoce e BRSValente, cultivadas em cinco diferentes épocas de semeadura, durante o inverno (Santo Antônio de Goiás, GO, 2001/2002). * significativo ( $<<0,05)$. ** significativo $(\mathrm{p}<0,01)$. Dados médios de quatro repetições.

Figura 2. Variações na taxa de acúmulo de $\mathrm{N}$ total (TAN), taxa de acúmulo de fitomassa total (TAFM) e taxa assimilatória líquida (TAL), determinadas no período compreendido entre a emergência e o início da floração (estádio R5), e quantidade de $\mathrm{N}$ total absorvido pela parte aérea, até o estádio R5, decorrentes da data de emergência de plantas de feijoeiro comum das cultivares Pérola, Jalo Precoce e BRS-Valente, cultivadas em cinco diferentes épocas de semeadura, durante o inverno (Santo Antônio de Goiás, GO, 2001/2002). * significativo $(\mathrm{p}<0,05)$.** significativo $(\mathrm{p}<0,01)$. Dados médios de quatro repetições. 
nor ou maior eficiência no uso do N (Boardman 1977, Muller et al. 2005, Hikosaka et al. 2006). Além disto, menores amplitudes térmicas aceleram o acúmulo de fitomassa, absorção e quantidade de nitrogênio total presente na parte aérea, indicando que, nem sempre, maiores quantidades de fitomassa e de $\mathrm{N}$ presentes na planta, no estádio R5, implicam em maior produtividade de grãos. Maiores produtividades de grãos, ao que tudo indica, podem ser esperadas quando as condições de ambiente favorecem menores taxas diárias de absorção de $\mathrm{N}$, com consequente maior eficiência do uso deste $\mathrm{N}$, no período de desenvolvimento das plantas de feijoeiro, até o terceiro trifólio.

\section{CONCLUSÕES}

1. Aumento da temperatura mínima, da radiação solar global incidente e da taxa diária de absorção de nitrogênio, até o terceiro trifólio, provocam redução no rendimento de grãos do feijoeiro.

2. A quantidade de fitomassa acumulada por unidade de $\mathrm{N}$, até o início do florescimento do feijoeiro, é reduzida à medida que a semeadura é efetuada, a partir de meados de abril até meados de agosto, e, quando esta redução ocorre até o terceiro trifólio, há, também, redução no rendimento de grãos.

3. Em épocas de semeadura do feijoeiro comum, nas quais o período entre emergência e início da floração coincide com maior amplitude térmica, as plantas terão menor índice de área foliar e maior potencial de rendimento de grãos.

\section{REFERÊNCIAS}

ABEBE, A.; BRICK, M. A.; KIRKBY, R. A. Comparison of selection indexes to identify productive dry beans lines under diverse environmental conditions. Field Crops Research, Amsterdam, v. 58, n. 1, p. 15-23, jul. 1998.

ACOSTA-GALLEGOS, J. A.; VARGAS-VASQUEZ, P.; WHITE, J. W. Effect of sowing date on the growth and seed yield of common bean (Phaseolus vulgaris L.) in highland environments. Field Crops Research, Amsterdam, v. 49, n. 1, p. 1-10, nov. 1996.

ATKIN, O. K.; TJOELKER, M. G. Thermal acclimation and the dynamic response of plant respiration to temperature. Trends in Plant Science, Oxford, v. 8, n. 7, p. 343-351, jul. 2003.

BOARDMAN, N. K. Comparative photosynthesis of sun and shade plants. Annual Review of Plant Physiology, Palo Alto, v. 28, n. 1, p. 355-377, 1977.
CARBONELL, S. A. M.; POMPEU, A. S. Estabilidade fenotípica de linhagens de feijoeiro em três épocas de plantio no Estado de São Paulo. Pesquisa Agropecuária Brasileira, Brasília, DF, v. 35, n. 2, p. 321-329, fev. 2000.

CARBONELL, S. A. M.; POMPEU, A. S. Estratificação de ambientes em experimentação de feijoeiro no Estado de São Paulo. Bragantia, Campinas, v. 56, n. 1, p. $207-$ 218, jan./jun. 1997.

DIDONET, A. D. Ecofisiologia e rendimento potencial do feijoeiro. In: DEL PELOSO, M. J.; MELO, L. C. (Eds.). Potencial de rendimento da cultura do feijoeiro comum. Santo Antônio de Goiás: Embrapa Arroz e Feijão, 2005. p. 9-37.

DIDONET, A. D.; VITÓRIA, T. B. Resposta do feijoeiro comum ao estresse térmico aplicado em diferentes estágios fenológicos. Pesquisa Agropecuária Tropical, Goiânia, v. 36, n. 3, p. 199-204, set./dez. 2006.

GRAHAM, P. H.; RANALLI, P. Common bean (Phaseolus vulgaris L.). Field Crops Research, Amsterdam, v. 53, n. 1-3, p. 131-146, jul. 1997.

GROSS, Y.; KIGEL, J. Differential sensitivity to high temperature of stages in the reproductive development of common bean (Phaseolus vulgaris L.). Field Crops Research, Amsterdam, v. 36, n. 3, p. 201-212, mar. 1994.

GUY, C. et. al. Metabolomics of temperature stress. Physiologia Plantarum, Copenhagen, v. 132, n. 2, p. 220235, fev. 2008.

HANSEN, J. et. al. Global temperature change. Proceedings of the National Academy of Science of the USA, Washington, DC, v. 103, n. 39, p. 14288-14293, set. 2006.

HIKOSAKA, K. Modeling optimal temperature acclimation of the photosynthetic apparatus in $\mathrm{C} 3$ plants with respect to nitrogen use. Annals of Botany, London, v. 80, n. 6, p. 721-730, dez. 1997.

HIKOSAKA, K. et. al. Temperature acclimation of photosynthesis: mechanisms involved in the changes in temperature dependence of photosynthetic rate. Journal of Experimental Botany, London, v. 57, n. 2, p. 291-302, jan. 2006.

JEUFFROY, M. H.; NEY B. Crop physiology and productivity. Field Crops Research, Amsterdam, v. 53, n. 1-3, p. 3-16, jul. 1997.

MIFLIN, B. Crop improvement in the $21^{\text {st }}$ century. Journal of Experimental Botany, London, v. 51, n. 342, p. 1-8, jan. 2000.

MIRANDA, G. V. et. al. Adaptabilidade e estabilidade de comportamento de cultivares de feijão em quatro municípios da zona da mata de Minas Gerais. Revista Ceres, Viçosa, v. 40, n. 232, p. 591-609, nov./dez. 1993. 
MITTLER, R. Abiotic stress, the field environment and stress combination. Trends in Plant Science, Oxford, v. 11, n. 1, p. 15-19, jan. 2006 .

MULLER, O.; HIKOSAKA, K.; HIROSE, T. Seasonal changes in light and temperature affect the balance between light harvesting and light utilization components of photosynthesis in an evergreen understorey. Oecologia, Berlin, v. 143, n. 4, p. 501-508, maio 2005.

PASTENES, C.; HORTON, P. Effect of high temperature on photosynthesis in beans. Plant Physiology, Bethesda, v. 112, n. 3, p. 1253-1260, nov. 1996.

PEREIRA, A. R. Aspectos fisiológicos da produtividade vegetal. Revista Brasileira de Fisiologia Vegetal, Londrina, v. 1, n. 2, p. 139-142, dez. 1989.

PIMENTEL, C. Metabolismo de carbono na agricultura tropical. Seropédica: Edur, 1998.

PORCH, T. G. Application of stress indexes for heat tolerance screening of common bean. Journal of Agronomy \& Crop Science, London, v. 192, n. 5, p. 390394, out. 2006.

RAINEY, K. M.; GRIFFITHS, P. D. Inheritance of heat tolerance during reproductive development in snap bean (Phaseolus vulgaris L.). Journal of the American Society for Horticultural Science, Mount Vernon, v. 130, n. 5, p. 700-706, set. 2005.

RAMALHO, M. A. P.; ABREU, A. F. B.; RIGHETTO, G. U. Interação de cultivares de feijão por épocas de semeadura em diferentes localidades do Estado de Minas Gerais. Pesquisa Agropecuária Brasileira, Brasília, DF, v. 28, n. 10, p.1183-1189, out. 1993.

RIBEIRO, R. V. et. al. Environmental effects on photosynthetic capacity of bean genotypes. Pesquisa Agropecuária Brasileira, Brasília, DF, v. 39, n. 7, p. 615623, jul. 2004.

SAGE, R. F.; KUBIEN, D. S. The temperature response of C3 and C4 photosynthesis. Plant, Cell and Environment, Oxford, v. 30, n. 9, p. 1086-1106, set. 2007.

SAMACH, A.; WIGGE, P. A. Ambient temperature perception in plants. Current Opinion in Plant Biology, Amsterdam, v. 8, n. 5, p. 483-486, out. 2005.
SCHOONHOVEN, A. van; VOYSEST, O. (Eds.). Common beans: research for crop improvement. Wallingford: $\mathrm{CAB}$; Cali: CIAT, 1991.

SHAO, L. et. al. Antioxidation of anthocyanins in photosynthesis under high temperature stress. Journal of Integrative Plant Biology, Beijing, v. 49, n. 9, p. 13411351, set. 2007.

SHULAEV, V. et. al. Metabolomics for plant stress response. Physiologia Plantarum, Copenhagen, v. 132, n. 2, p. 199-208, fev. 2008.

SILVA, F. B.; RAMAlHO, M. A. P.; ABREU, A. F. B. Seleção recorrente fenotípica para florescimento precoce de feijoeiro "Carioca”. Pesquisa Agropecuária Brasileira, Brasília, DF, v. 42, n. 10, p. 1437-1442, out. 2007.

TEDESCO, M. J. et. al. Análises de solo, plantas e outros materiais. 2. ed. Porto Alegre: UFRGS, 1995.

WAHID, A. et. al. Heat tolerance in plants: an overview. Environmental and Experimental Botany, Elmsford, v. 61, n. 3, p. 199-223, dez. 2007.

WELSH, W. et. al. Characterization of agronomic traits and markers of recombinant inbread lines from intraand interracial populations of Phaseolus vulgaris L. Theoretical and Applied Genetics, Berlin, v. 91, n. 1, p. 169-177, jul. 1995.

WHITE, J. W.; IZQUIERDO, J. Dry bean: physiology of yield potential and stress tolerance. Santiago: FAO, 1989.

WHITE, J. W. et. al. Inheritance of seed yield, maturity and seed weight of common bean (Phaseolus vulgaris) under semi-arid rainfed conditions. Journal of Agricultural Science, Cambridge, v. 122, n. 2, p. 265-273, abr. 1994.

WHITE, J. W.; SINGH, S. P. Source and inheritance of earliness in tropically adapted indeterminate common bean. Euphytica, Wageningen, v. 55, n. 1, p. 15-19, maio 1991. 